\title{
Mechanical Properties and Characterization of Similar and Dissimilar Spot Welding Joints
}

\author{
Abdul-Raheem Kadhum A. Ali, Nawal Mohammed Dawood and Ahmed Saleh Al-Graite \\ Department of Metallurgy, Collage of Materials Eengineering, University of Babylon, Babil, Iraq \\ Aaabidalieng@gmail.com, nawalmohammed2018@gmail.com, ahmed.agc040@gmail.com
}

\begin{abstract}
Increasing utilization of spot weld joints in engineering industry, especially in the automotive had led to need the deep knowledge of it. A 1 mm thickness of both mild steel and 304 stainless steel that was welded by spot welding at different condition. In spot welding process, the time and current of the welding were changed from $(0.2-0.5 \mathrm{sec})$ and from $(4-7 \mathrm{kA})$, respectively. The tensile-shear, coach-peel tests and failure modes of spot welding were investigated. Also, the optical microstructure and Vickers hardness were observed. The results showed the increase in welding current and time guide to increase the strength and hardness of the joints where the base metal hardness is lower about 2 times than the welded zone hardness. The joints strength at shear test is a higher than that at peel test and the pullout mode was showed in both the tensile-shear and peel test.
\end{abstract}

Key words: Spot welding, tensile-shear, coach-peel, failure mode, hardness, joints

\section{INTRODUCTION}

Resistance Spot Welding (RSW) is an essential welding method for welded metals in different manufactures. In these days, a car has spot welded about 2000-5000 (Anijdan et al., 2018; Abadi and Pouranvari, 2010; Jaber and Kovacs, 2018). RSW methods are widely utilized for welding mild steel, low-alloy steel, stainless steel, aluminum and copper alloys (Martin et al., 2009).

In the spot welding process, the welding is done due to the heat formed by the electrical resistance between two or three overlapped that were to be welded together (Aslanlar et al., 2008). The heat, pressure and time are combined to made the weld (Aslanlar, 2006). The research-piece resisted the electric current that passing through the materials to be welded to produce the heat that is necessary for these resistance welding methods (Aslanlar et al., 2008).

The different steel welding has become a necessary recent engineering procedure and important in vehicle industry (Wang et al., 2014) because of its advantages which are economical and easy to automate and require minimum skill also in metal construction, the spot welding resistance is the most important welded way (Pouranvari et al., 2011). The different materials joining are very universal in automotive structure (Wei et al., 2017). So as to modify material properties for necessities in automotive purposes, a different union of material thickness and type are specified and taking on variant metal joining supply probabilities for the flexible design of the manufactured goods by every material efficiently (Khan et al., 2009).

Dissimilar steels welding has several problems which are associated to the unlike welded materials properties such as (chemical, physical and mechanical) but the 304SS and LCS has a good joining of mechanical properties, weldability and corrosion resistance, so as to extensively use in the power generation industry (Kolarik et al., 2012). Dissimilar welding can be more difficult than similar because of unlike thermal cycle (Marashi et al., 2008).

Wang et al. (2014) examined the effect of spot welding condition on mild steel and 304SS weld joints. The results showed that the strength of TS test and diameter of nugget increased through the rising of current and time. Wei et al. (2017) studied the similar and dissimilar RSW of the DP steel and TRIP steel in variant welding and heat treatment conditions. They confirmed that the

Corresponding Author: Abdul-Raheem Kadhum A. Ali, Department of Metallurgy, Collage of Materials Eengineering, University of Babylon, Babil, Iraq 
suitable pre heating process enhanced the welding expulsion to several amount and the appropriate post-heating process enhanced the spot welds mechanical properties in consequence of the weld microstructure temper. Vinoth and Saravanan (2016) studied a parametric study in dissimilar spot welded joints at different welding conditions to get a better welding.

Mechanical and metallurgical properties of the FZ and HAZ changes after spot welding, so that, the study of these varies is essential for the safety of welded joints strength (Ozyurek, 2008). This study investigated mechanical properties and characterization of similar and dissimilar spot welding joints.

\section{MATERIALS AND METHODS}

About 304 stainless steel and mild steel with a $1 \mathrm{~mm}$ thickness were used and have the chemical compositions scheduled in Table 1. The materials were cut in sheets with $(80.30 .1 \mathrm{~mm})$ a dimensions that's seen in Fig. 1. Spot welding was achieved using an ESAB resistance spot welding machine. Welding was carried out with a $45^{\circ}$ truncated cone RWMA (Cu-Cr-Zr) electrode with a face diameter $(10 \mathrm{~mm})$. Similar and dissimilar sheets of mild steel/mild steel and mild steel/304 stainless steel were spot welded, respectively. Electrode force was kept constant at $3 \mathrm{kN}$ but the current was changed from (4-7 kA) as $1 \mathrm{kA}$ step and the welding time changed from $(0.2-0.5 \mathrm{sec})$, respectively as shown in Table 2.

Three welded specimens of each parameter were utilized. One of the specimens to make a tensile-shear test that is shown in Fig. 1 one specimen was used for hardness and microstructure observation as shown in Fig. 2 and another one specimen used for the coach-peel test as shown in Fig. 3. The specimens of microstructure were cut by a hydraulic
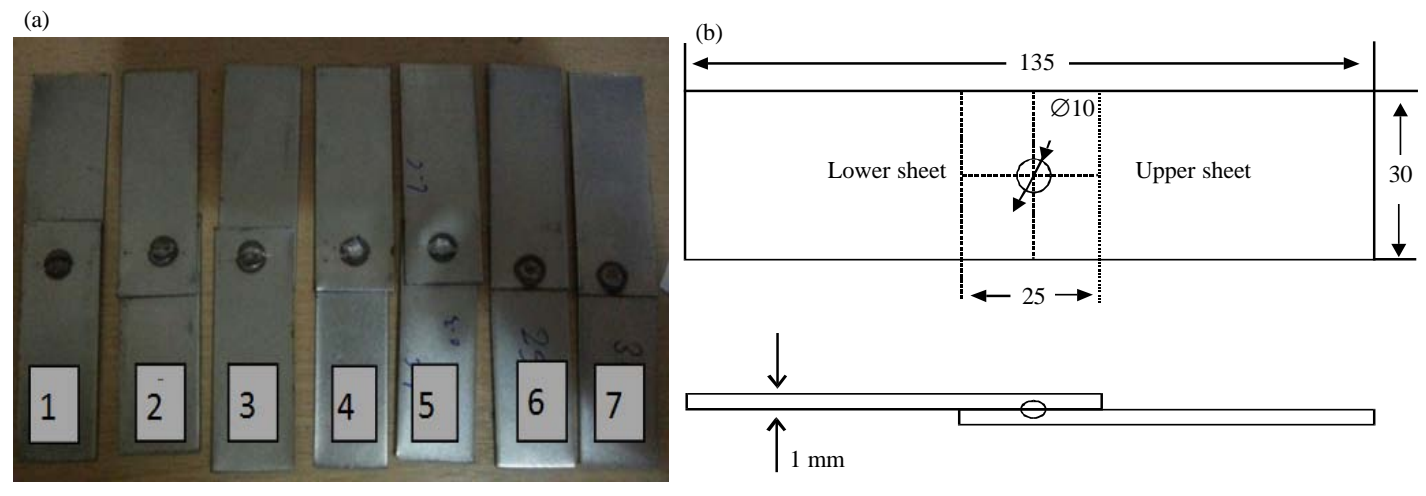

Fig. 1: a and b) Tensile shear test sample

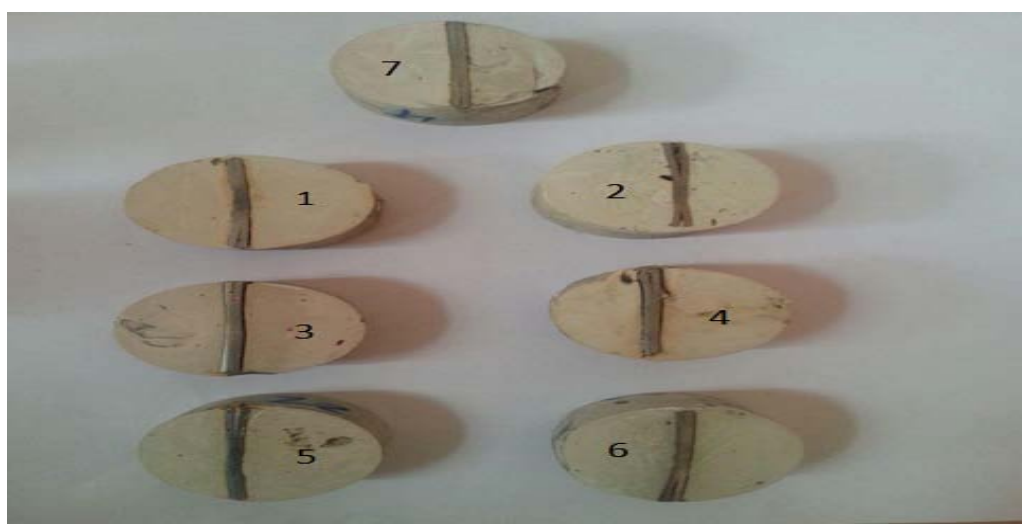

Fig. 2: Sample for microstructure and hardness 
Table 1: The chemical composition of the materials used

\begin{tabular}{|c|c|c|c|c|c|c|c|c|c|c|}
\hline Samples & $\mathrm{C}(\%)$ & $\mathrm{Si}(\%)$ & $\mathrm{Mn}(\%)$ & $\mathrm{P}(\%)$ & $\mathrm{S}(\%)$ & $\mathrm{Cr}(\%)$ & $\mathrm{Ni}(\%)$ & $\mathrm{Al}(\%)$ & $\mathrm{Cu}(\%)$ & $\mathrm{Fe}(\%)$ \\
\hline LCS & 0.0244 & 0.058 & 0.182 & 0.0048 & 0.0100 & & & & & Bal \\
\hline 304.SS & 0.0545 & 0.369 & 0.983 & 0.0380 & 0.0005 & 19.02 & 7.99 & 0.001 & 0.038 & Bal \\
\hline
\end{tabular}

Table 2: The welding parameters

\begin{tabular}{|c|c|c|c|c|}
\hline Parameters & Electrode tip (mm) & Welding current $(\mathrm{kA})$ & Welding time (sec) & Electrode force $(\mathrm{kN})$ \\
\hline $1 \& 8$ & 10 & 4 & 0.2 & 3 \\
\hline $2 \& 9$ & 10 & 5 & 0.2 & 3 \\
\hline $3 \& 10$ & 10 & 6 & 0.2 & 3 \\
\hline $4 \& 12$ & 10 & 7 & 0.2 & 3 \\
\hline $5 \& 12$ & 10 & 7 & 0.3 & 3 \\
\hline $6 \& 13$ & 10 & 7 & 0.4 & 3 \\
\hline $7 \& 14$ & 10 & 7 & 0.5 & 3 \\
\hline
\end{tabular}

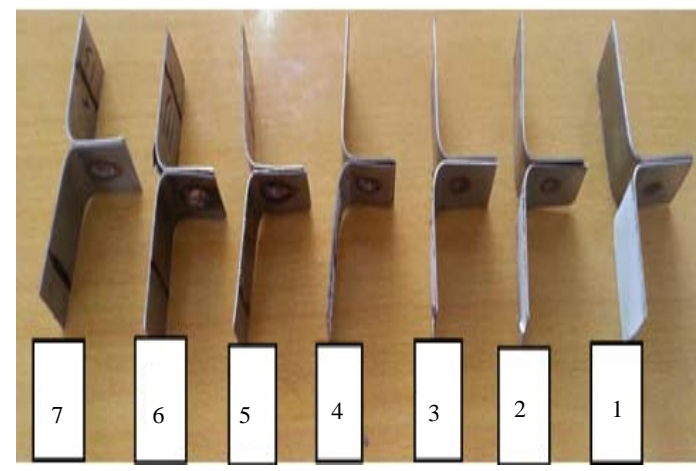

Fig. 3: Test sample for coach-peel test

punch. After grinding using rough and fine emery and polishing, the specimen was etched in a solution of ( $2 \mathrm{~mL} \mathrm{HNO}_{3}$ and $98 \mathrm{~mL}$ ethanol for $\left.30 \mathrm{sec}\right)$ for mild steel but for $304 \mathrm{SS}$, the mixture from $(8.5 \mathrm{~g}$ $\mathrm{FeCl}+2.4 \mathrm{~g} \mathrm{CuCl}+122 \mathrm{~mL}$ Ethanol $122 \mathrm{HCl}+6 \mathrm{~mL}$ $\mathrm{HNO}_{3}$ ) for $3 \mathrm{sec}$ was used.

The microstructure of the specimen was examined by optical microscope but the hardness was performed by a Vickers hardness measurement device at $200 \mathrm{~g}$ load. Shear tests were done on a universal device with a speed of $0.2 \mathrm{~mm} / \mathrm{m}$ but a united test machine at speed of tension of $0.1 \mathrm{~mm} / \mathrm{m}$ was used to couch peel tests.

\section{RESULTS AND DISCUSSION}

Microstructure examination: In base metal of both 304 SS side and LCS side, the dissimilar microstructure can be observed. The microstructure of LCS base metal used in this study is ferritic with a some of pearlite as shown in Fig. 4 but the base metal of $304 \mathrm{SS}$ is austenite with a delta-ferrite structure which shown in Fig. 4.

Austenitic stainless steel base metal is an untransformable, so, no phase varies happens in the $\mathrm{HAZ}$ and FZ of stainless steel side except their grain
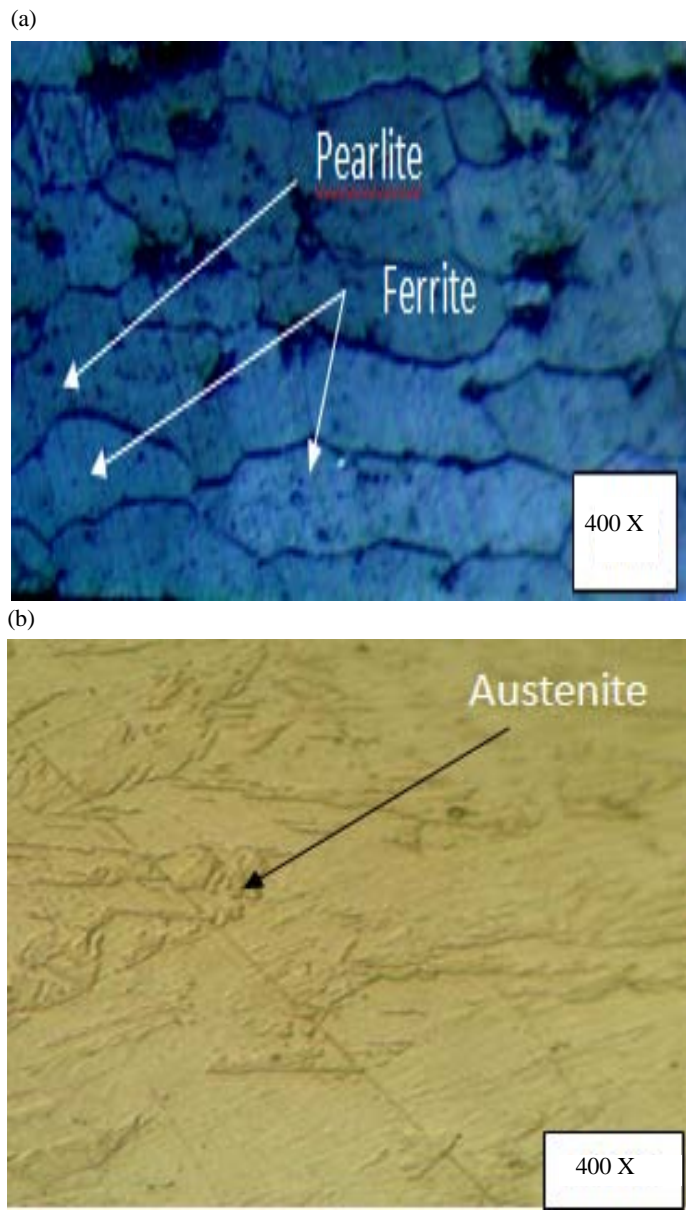

Fig. 4: The microstructure of the BMZ for: a) LCS and b) $304 \mathrm{SS}$

growth but the HAZ and FZ structure of mild steel is martensite, grain boundary ferrite and Widmanstatten ferrite as shown in Fig. 5-6. In dissimilar welding, the line of final solidification is not situated at sheet/sheet border but moves to the higher resistively side at this time, austenite stainless steel which can affect the mechanical performance. 

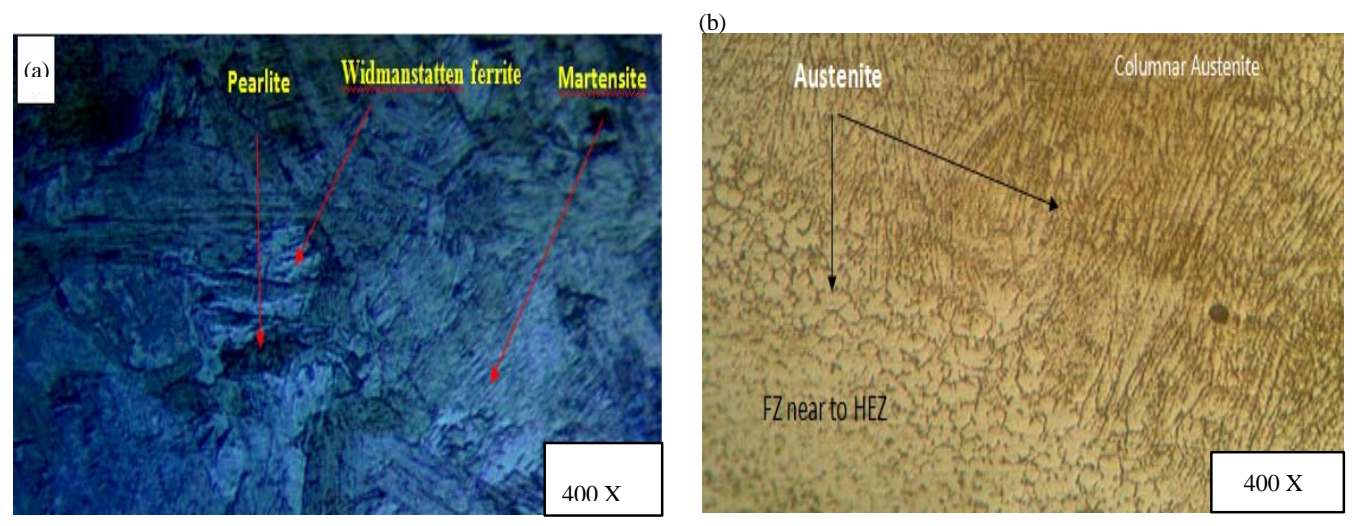

Fig. 5: The microstructure of the HEZ for: a) LCS and b) 304 SS
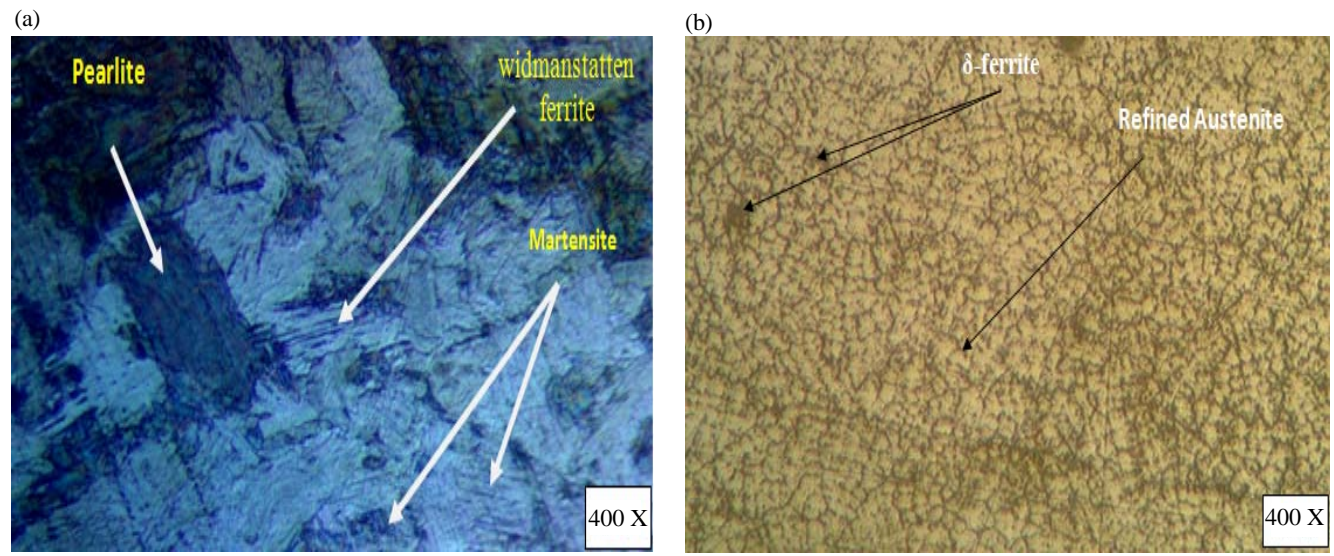

Fig. 6: The microstructure of the FZ for:a):LCS and b) 304 SS

Table 3: Effect the welding current and time on max load of dissimilar welding

\begin{tabular}{llcccc}
\hline Parameters & Materials & Current $(\mathrm{kA})$ & Time $(\mathrm{sec})$ & Peak load $(\mathrm{TS}, \mathrm{kN})$ & Peak load $(\mathrm{CP}, \mathrm{kN})$ \\
\hline 1 & LCS/LCS & 4 & 0.2 & 5.859 & 1.1451 \\
2 & LCS/LCS & 5 & 0.2 & 6.055 & 1.1496 \\
3 & LCS/LCS & 6 & 0.2 & 6.543 & 1.1722 \\
4 & LCS/LCS & 7 & 0.2 & 6.641 & 1.1966 \\
5 & LCS/LCS & 7 & 0.3 & 6.642 & 1.2051 \\
6 & LCS/LCS & 7 & 0.4 & 6.836 & 1.3580 \\
7 & LCS/LCS & 7 & 0.5 & 6.935 & 1.5078 \\
8 & LCS/304SS & 4 & 0.2 & 6.348 & 0.8825 \\
9 & LCS/304SS & 5 & 0.2 & 6.450 & 1.0065 \\
10 & LCS/304SS & 6 & 0.2 & 6.640 & 1.0676 \\
11 & LCS/304SS & 7 & 0.2 & 6.641 & 1.1072 \\
12 & LCS/304SS & 7 & 0.3 & 6.930 & 1.1174 \\
13 & LCS/304SS & 7 & 0.4 & 6.930 & 1.1439 \\
14 & LCS/304SS & 7 & 0.5 & 7.129 & 1.1448 \\
\hline
\end{tabular}

Micro-hardness results: The weld nugget hardness of the dissimilar spot welding is larger than that in the similar spot welding which attributed to the hardness of 304 SS. In different condition of welding the nugget hardness of similar welding increased from (234-274 HV) as compared with the dissimilar welding that increased from (389-433 HV). The FZ hardness is large a nearly to 2 times of the base metal hardness as in the Fig. 7 and 8.
Tensile-shear test result: As can be seen in Fig. 9 and 10 and Table 3, increment of the welding current and welding time increased spot weld strength due to increase the diameter of nugget.

In the similar welding, the weld strength increased from 5.859-6.641 $\mathrm{kN}$ by increasing the welding current from 4-to-7 kA with constant other. When the welding time changed from $0.2-0.5 \mathrm{sec}$ with 

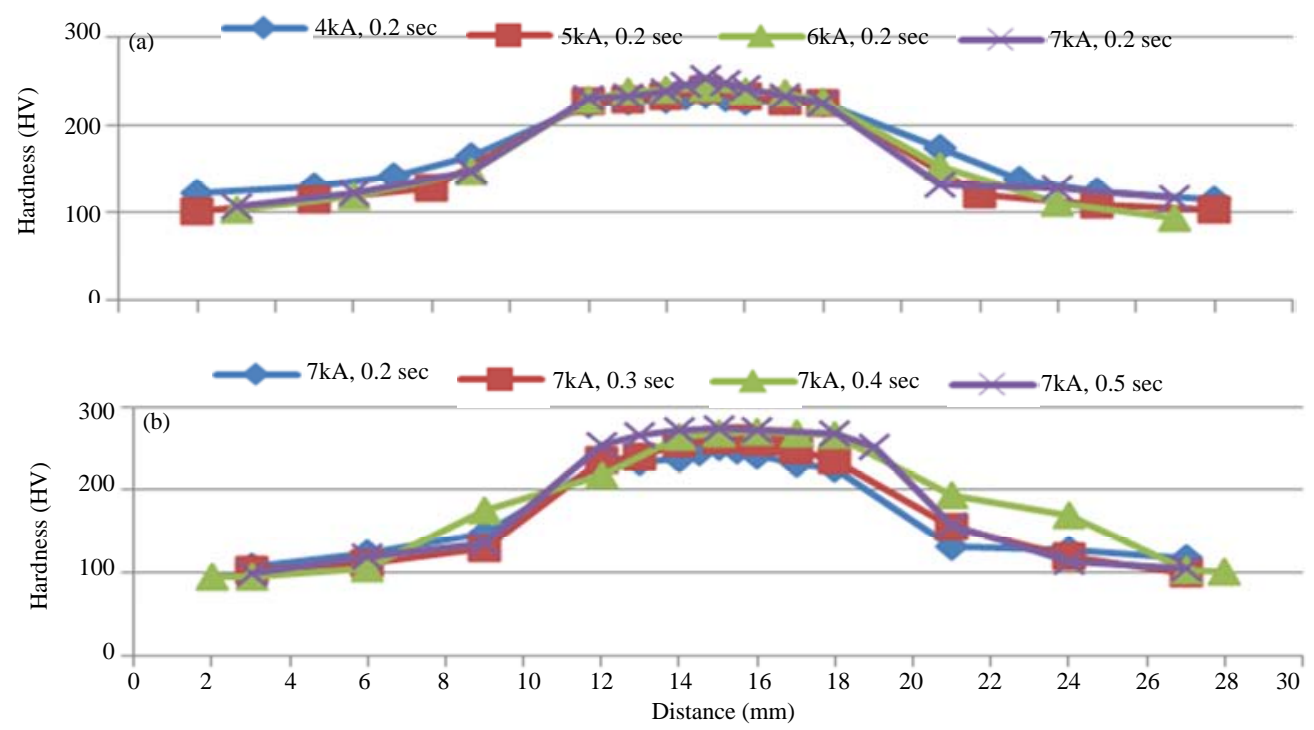

Fig. 7: The hardness survey of LCS/LCS for: a) Different current and b) Different time

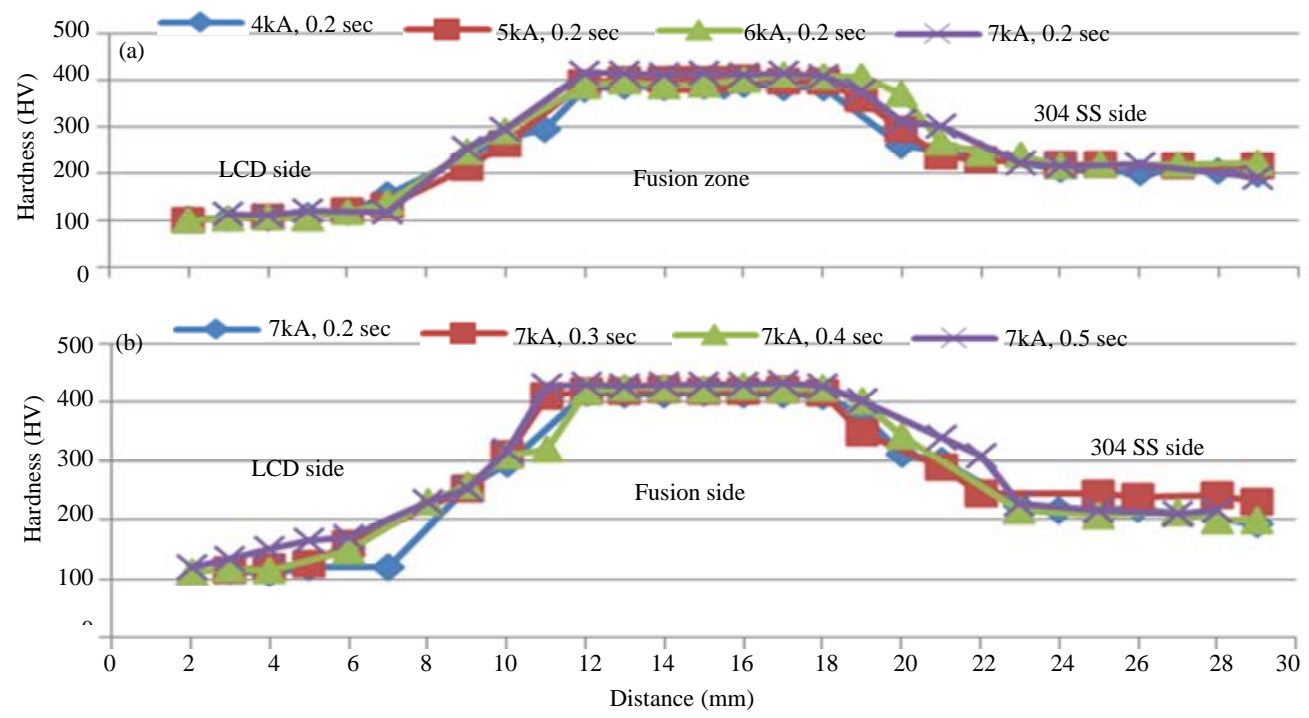

Fig. 8: Hardness survey for LCS/304SS joints for: a) Different current and b) Different time

constant other parameters (current and electrode force), the weld strength increased from 6.641-6.934 $\mathrm{kN}$ as in Fig. 9.

But in the dissimilar spot welding as the welding current increasing from (4-7 kA) with constant other parameters, the peak load increases from $(6.348-6.934 \mathrm{kN})$. The shear strength increases from $(6.934-7.129 \mathrm{kN})$ in four period welding times from $(0.2-0.5 \mathrm{sec})$ as shown in Fig. 10. As a result for the similar and dissimilar RSW, the peak load of LCS/LCS and $304 \mathrm{SS} / \mathrm{LCS}$ is nearly same. This is as a result of the actuality that the PF mode of 304 SS/LCS joints is initiated from LCS base metal.
Coach-peel test result: Once a weld nugget formed, the weld failure or button pullout occurs when the nugget diameter is small, so, the joints normally failed through the nugget or by a button pullout as it is above a certain size. The behavior of coach-peel test for dissimilar RSW was like the behavior of similar RSW because of the truth that the failure mode of 304SS/LCS joints was began from LCS base metal as shown in the Fig. 11 and 12.

\section{Failure modes}

Pullout failure of tensile-shear test specimen: Two failure modes can be noticed through the RSW 

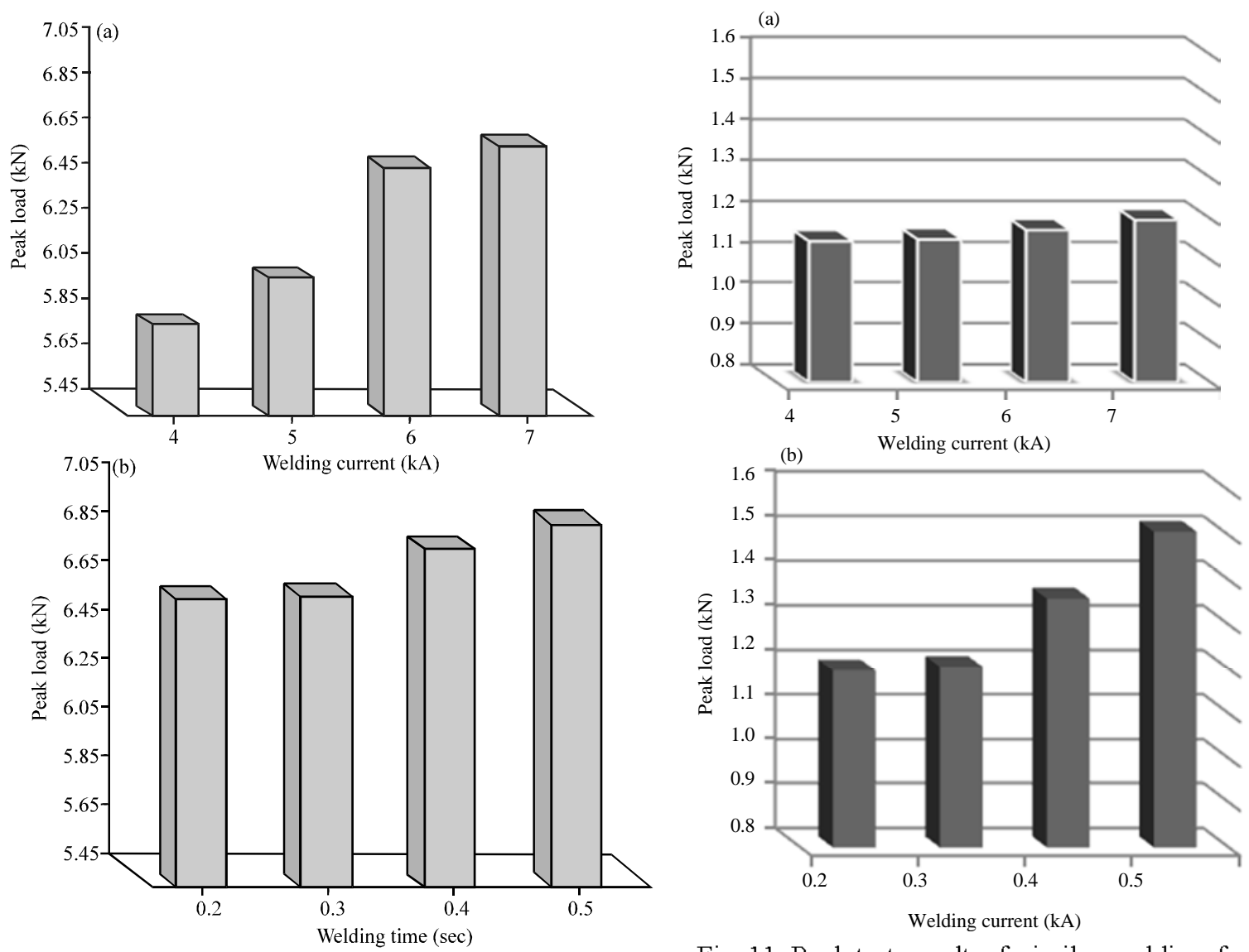

Fig. 9: Shear test result of similar welding for: a) Different current and b) Different time
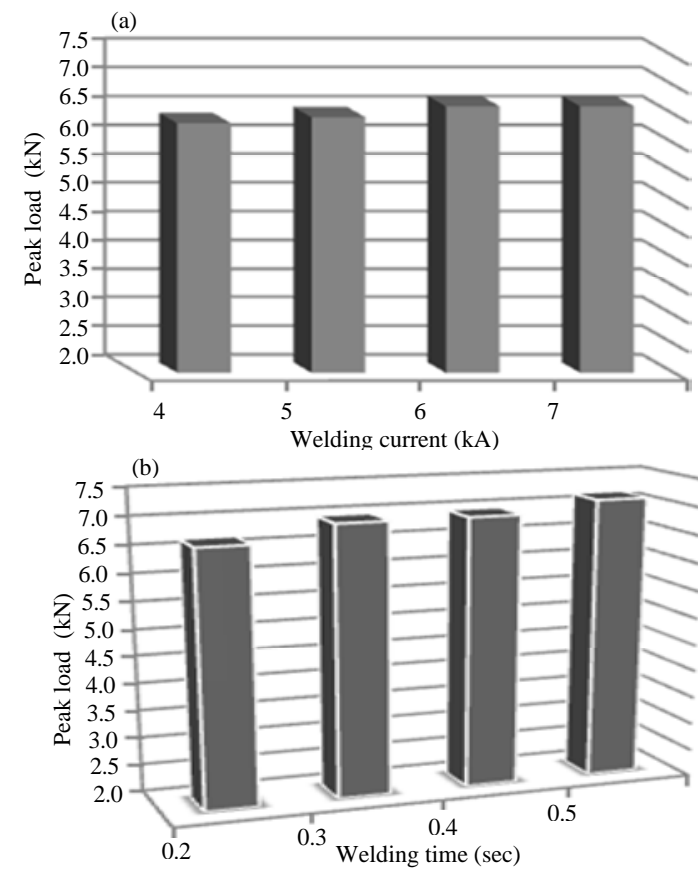

Fig. 11: Peel test result of similar welding for: a) Different current and b) Different time
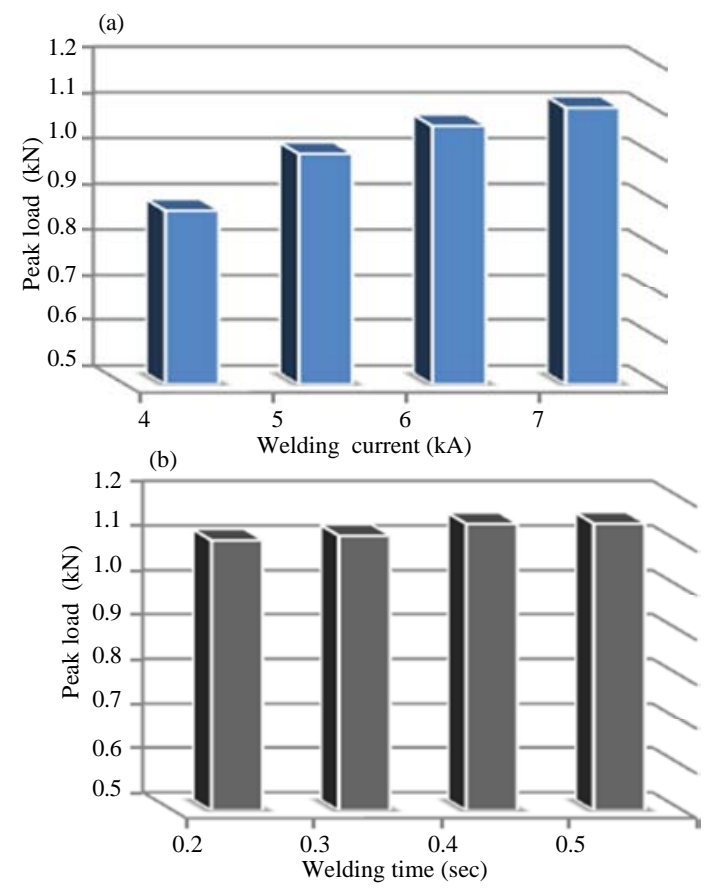

Fig. 10: Shear test result of dissimilar welding for: a) Different current and b) different time

Fig. 12: Peel test result of dissimilar welding for: a) Different current and b) Different time 


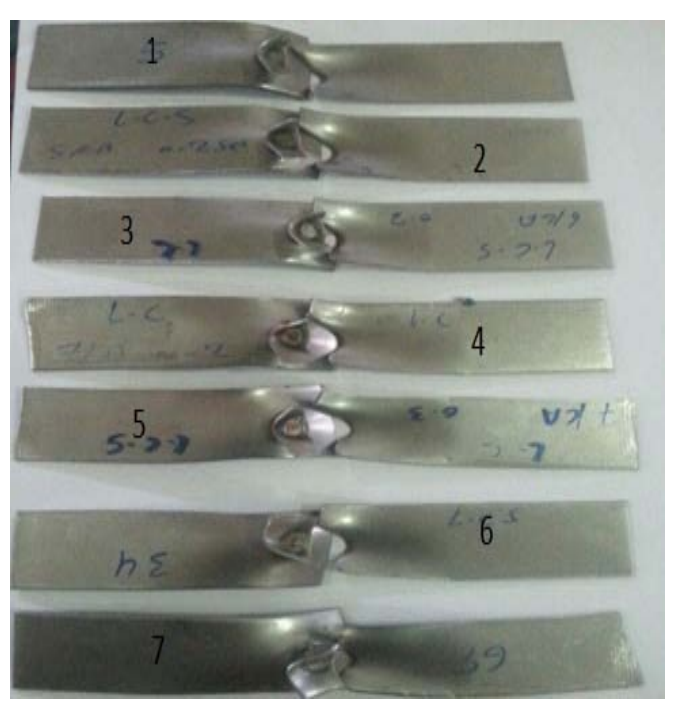

Fig. 13: The failure mode of shear test

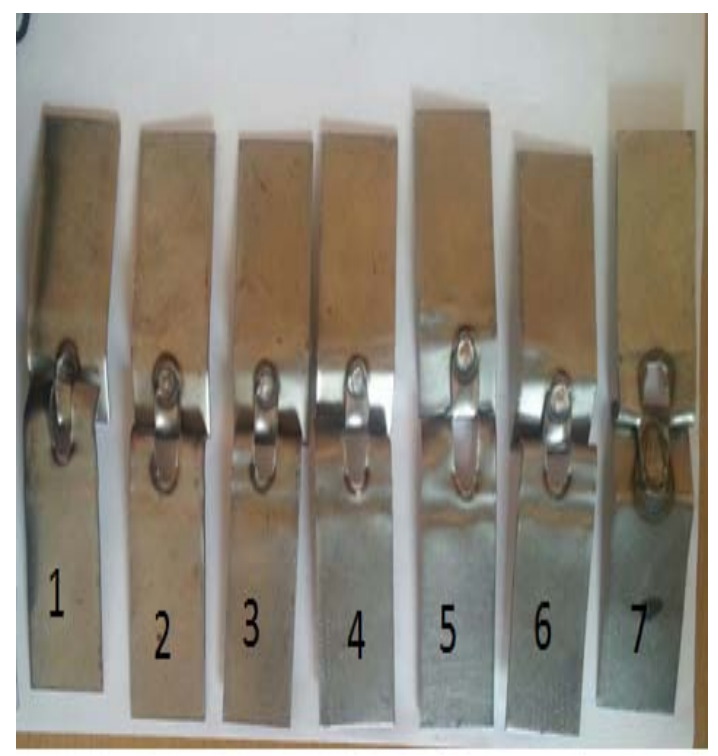

Fig. 14: The failure mode of peel test

pullout and interfacial mode. In the interfacial failure mode, the driving force is shear stress and a high shear stress is formed at the interface. A pullout failure mode initiated around the nugget to the lower hardness LCS sheet due to it's the lower resistance region to plastic deformation and then propagated by necking/shear around the nugget until the upper sheet is turned off. Failure mode can be observed through the shear test that is a pullout mode as shown in Fig. 13.
Pullout failure of coach-peel specimens: Pullout failure in the peel test is accompanied by crack initiation and propagation. Crack initiates closest to the notch tip at the faying surface or close to it and the crack initiation site are happens in the coarse-grained HAZ. Final fracture happens as the crack propagates at thickness of the sheet. For all the RSW peel joints, the nugget was pulled out of one of the sheets (Han et al., 2010) and the failure mode that obtained of peel test as shown in Fig. 14 which is attributed to a certain size of weld nugget and a right welded joint.

\section{CONCLUSION}

From the obtained results and their discussion several conclusions may be drawn as follow:

- The FZ hardness is large a nearly to 2 times of the base metal hardness

- The peak load of similar and dissimilar RSW is nearly same

- The peak load of peel test is lower than shear test

- Failure mode can be observed through the shear and peel tests is a pullout mode

\section{REFERENCES}

Abadi, M.M.H. and M. Pouranvari, 2010. Correlation between macro/micro structure and mechanical properties of dissimilar resistance spot welds of AISI 304 Austenitic stainless steel and AISI 1008 low carbon steel. Assoc. Metall. Eng. Serb. AMES., 16: 133-146.

Anijdan, S.M.H., M. Sabzi, M. Ghobeiti-Hasab and A. Roshan-Ghiyas, 2018. Optimization of spot welding process parameters in dissimilar joint of dual phase steel DP600 and AISI 304 stainless steel to achieve the highest level of shear-tensile strength. Mater. Sci. Eng. A., 726: 120-125.

Aslanlar, S., 2006. The effect of nucleus size on mechanical properties in electrical resistance spot welding of sheets used in automotive industry. Mater. Des., 27: 125-131.

Aslanlar, S., A. Ogur, U. Ozsarac and E. Ilhan, 2008. Welding time effect on mechanical properties of automotive sheets in electrical resistance spot welding. Mater. Des., 29: 1427-1431.

Han, L., M. Thornton and M. Shergold, 2010. A comparison of the mechanical behaviour of self-piercing riveted and resistance spot welded Aluminium sheets for the automotive industry. Mater. Des., 31: 1457-1467. 
Jaber, H. and T. de Kovacs, 2018. Similar and dissimilar resistance spot welds of DP600 and X8Cr1 7 steels sheets: Welding current and fracture toughness. Banki Kozlemenyek, 1: 67-72.

Khan, M.S., S.D. Bhole, D.L. Chen, E. Biro and G. Boudreau et al., 2009. Welding behaviour, microstructure and mechanical properties of dissimilar resistance spot welds between galvannealed HSLA350 and DP600 steels. Sci. Technol. Weld. Joining, 14: 616-625.

Kolarik, L., M. Sahul, M. Kolarikova, M. Sahul and M. Turna et al., 2012. Resistance spot welding of dissimilar steels. Acta Polytech., 52: 43-47.

Marashi, P., M. Pouranvari, S. Amirabdollahian, A. Abedi and M. Goodarzi 2008. Microstructure and failure behavior of dissimilar resistance spot welds between low carbon galvanized and austenitic stainless steels. Mater. Sci. Eng., A480: 334-346.

Martin, O., P.D. Tiedra, M. Lopez, M. San-Juan, C. Garcia, F. Martin and Y. Blanco, 2009. Quality prediction of resistance spot welding joints of 304 austenitic stainless steel. Mater. Des., 30: 68-77.
Ozyurek, D., 2008. An effect of weld current and weld atmosphere on the resistance spot weldability of 304L austenitic stainless steel. Mater. Des., 29: 597-603.

Pouranvari, M., S.P.H. Marashi and S.M. Mousavizadeh, 2011. Dissimilar resistance spot welding of DP600 dual phase and AISI 1008 low carbon steels: Correlation between weld microstructure and mechanical properties. Ironmaking Steelmaking, 38: 471-480.

Vinoth, T.M. and M. Saravanan, 2016. Parametric study in spot welding for dissimilar weld joints. Intl. J. Innovative Res. Sci., 5: 10704-10711.

Wang, N., R. Qiu, W. Peng and H. Shi, 2014. Resistance spot welding between mild steel and stainless steel. Appl. Mech. Mater., 677: 23-26.

Wei, S.T., D. Lv, R.D. Liu and L. Lin, 2017. Similar and dissimilar resistance spot Weldability of Galvanised DP1000 and TWIP980 steels. Sci. Technol. Weld. J., 22: 278-286. 